\title{
Definition of the Molecular and Cellular Mechanisms Underlying the Tissue-selective Agonist/Antagonist Activities of Selective Estrogen Receptor Modulators
}

\author{
Donald P. McDonnell, Caroline E. Connor, Ashini Wijayaratne, \\ ChING-YI Chang, AND John D. NORRIS \\ Department of Pharmacology and Cancer Biology, Duke University Medical Center, \\ Durham, North Carolina 27710
}

\begin{abstract}
The term selective estrogen receptor modulators describes a group of pharmaceuticals that function as estrogen receptor (ER) agonists in some tissues but that oppose estrogen action in others. Although the name for this class of drugs has been adopted only recently, the concept is not new, as compounds exhibiting tissue-selective ER agonist/antagonist properties have been around for nearly 40 years. What $i s$ new is the idea that it may be possible to capitalize on the paradoxical activities of these drugs and develop them as target organ-selective ER agonists for the treatment of osteoporosis and other estrogenopathies. This realization has provided the impetus for research in this area, the progress of which is discussed in this review.
\end{abstract}

\section{Introduction}

Selective estrogen receptor modulators (SERMs) are a class of estrogen receptor (ER) ligands that, depending on the cell and tissue in which they operate, can function as agonists or antagonists (McDonnell, 1999). Initially classified as partial agonists, the realization that the relative agonist/antagonist activities of SERMs can differ between cells has indicated that they constitute a pharmacologically distinct class of compounds. This misclassification was apparent as early as 1967 when the properties of the "anti-estrogen" tamoxifen were first described. Specifically, it was observed that this compound could function as an antagonist in the reproductive systems of mice, a partial agonist in rats, and a pure antagonist in chickens (Harper and Walpole, 1967). The true significance of these findings - which indicated that tamoxifen could oppose estrogen action in some environments but mimic the action of the hormone in others - was not realized until much later, although, in retrospect, it was clear that the SERM concept was already developing (Kurl and Borthwick, 1980; Beall et al., 1984; Turner et al., 1987). It was not until a randomized clinical study, aimed at evaluating the impact of tamoxifen chemotherapy on skeletal integrity in breast 
cancer patients, was performed that the beneficial effects of SERM action became clear (Love et al., 1992). Unexpectedly, it was found that although tamoxifen functioned as an anti-estrogen in breast, it exhibited significant estrogenic activity in the skeletal and cardiovascular systems. These compelling data suggested that SERMs might have utility outside the realm of oncology as treatments for osteoporosis, cardiovascular disease, and other conditions associated with hypoestrogenicity. Indeed, were it not for the fact that tamoxifen can function as an ER agonist in the uterus and elevates a woman's risk of getting uterine cancer, it is possible that this drug could have been developed as an antiresorbtive therapy for osteoporosis (Ismail, 1994). Fortunately, other compounds were available that had more favorable therapeutic profiles. One drug in particular, keoxifene (subsequently renamed raloxifene), was found to function similarly to tamoxifen (as an anti-estrogen) in breast tumors but functioned as a pure antagonist in the uterus (Clemens et al., 1983; Poulin et al., 1989). This drug emerged from a discovery program aimed at developing an anti-estrogen that could be used for the treatment of tamoxifen-refractory breast cancers. Whereas it was not found to be effective as a breast cancer chemotherapeutic, its ability to function as an agonist in bone, but not uterus, led to the approval of this drug for the treatment and prevention of osteoporosis (Turner et al., 1994; Black et al., 1994). Thus, the SERM concept was established and the search for improved drugs of this class took off and continues today at a frantic pace.

\section{The Unmet Medical Need for SERMs with Improved Therapeutic Profiles}

The therapeutic profile of raloxifene makes it appealing to women who do not want to take classical estrogen-containing medicines. However, it is clearly not a substitute for established estrogen replacement therapies (Delmas et al., 1997; Ettinger et al., 1999). On the positive side, it was determined that raloxifene was about $30 \%$ as effective as estrogen in bone, had insignificant uterotrophic activity, and lowered low-density lipoprotein-cholesterol without elevating triglycerides (Delmas et al., 1997). Unlike estrogen, it was unable to suppress hot flashes and exacerbated other climacteric conditions associated with menopause (Delmas et al., 1997). However, the main impediments to a wider acceptance of the existing SERMs are the unknowns. Estrogens have been shown to have beneficial effects in the cardiovascular and central nervous system (CNS) (Zumoff, 1993; Yaffe et al., 1998). However, since we do not know the mechanism(s) underlying these positive activities of estrogens, there is a possibility that administration of a SERM, which has the potential to manifest agonist or antagonist activity, may lead to a deterioration of function in these systems. These limitations not withstanding, it is the initial data that demonstrated that breast cancer incidence could be reduced by up to $72 \%$ in postmenopausal 
women taking raloxifene that suggested that SERMs will become a mainstream medicine (Cummings et al., 1999). Although it remains to be seen if this initial suppression of breast cancer incidence translates into improvements in survival, this finding has encouraged pharmaceutical manufacturers to launch major efforts to search for the perfect SERM (Willson et al., 1997; Ke et al., 1998). Clearly, despite the beneficial effects of raloxifene, it is generally held that better SERMs remain to be identified. From what is known about the next generation of SERMs now under development, it appears that they will display an advantage over raloxifene with respect to potency (Ke et al., 1998; Neven, 2000). Apart from improved pharmaceutical properties, however, it is not clear if secondgeneration SERMs will have a therapeutic profile that is better than raloxifene. It is likely that, as we begin to understand the molecular mechanisms that determine the relative agonist/antagonist activities of these first- and secondgeneration SERMs, we will be in a position to develop mechanism-based screens for compounds with improved therapeutic profiles. Since millions of years of evolution have enabled cell-signaling systems to optimally recognize the ERestradiol complex, it is unlikely that a compound can be developed that will possess all of the positive and none of the negative attributes of estradiol. However, given what we have learned thus far about estrogen action, it does appear that we can improve over current SERMs and that, in the future, we may have an expanded family of such compounds that may have different target site specificities. How - and in what direction - this field develops is now in the hands of the basic scientist. It is unlikely that truly novel therapies can be developed until the mechanisms of action of estrogens and SERMs in bone, the CNS, or the cardiovascular system are known and this information is incorporated into drug screens.

\section{Lessons in SERM Action from Studying Tamoxifen Resistance}

Until recently, tamoxifen was considered to have a relatively simple mechanism of action, functioning as a competitive antagonist that opposed the binding of estrogen to its receptor (Clark and Peck, 1979; Clark and Markaverich, 1988). Not surprisingly therefore, much of the past research on this drug has focused on defining how it functioned as an anti-estrogen. Now, research interests have broadened to probe the mechanism(s) by which the SERM activity of tamoxifen is manifest. Some investigators have focused on determining how resistance to tamoxifen arises in breast tumors, whereas others are interested in how it (and related compounds) can function as tissue-selective agonists/antagonists. We believe that these two apparently dichotomous actions of tamoxifen are, in fact, related. Thus, several years ago, we considered that insights into SERM action could be gained from studying the mechanism(s) by which breast cancer cells escape the antagonist actions of tamoxifen. 
Tamoxifen was initially approved as an anti-estrogen in 1978 for the treatment of metastatic breast cancer and as an adjuvant chemotherapeutic in noninvasive disease (Osborne, 1998). A large number of studies have demonstrated a significant impact of this drug on both disease-free and overall survival (Gockerman et al., 1986; Fisher et al., 1996,2001; Early Breast Cancer Trialists' Collaborative Group, 1998). However, in the metastatic setting, tamoxifen failure (resistance) eventually arises within the first 5 years of treatment (Touchette, 1992; Tonetti and Jordan, 1995). Initially, this was considered to reflect classical resistance where receptor mutations, changes in tamoxifen metabolism, or multiple drug resistance systems were considered to be the primary mechanism(s) responsible (Osborne et al., 1991,1992; Sluyser, 1992; Karnik et al., 1994; Tonetti and Jordan, 1995). However, several pieces of evidence have suggested that it may not be as simple as initially suspected and that failure actually may reflect a change in the biocharacter of tamoxifen in which it switches from being recognized by cells as an antagonist to an agonist (LegaultPoisson et al., 1979; Canney et al., 1987; Hu et al., 1993; Norris et al., 1999; Connor et al., 2001). This contention is clearly supported by the fact that a significant number of patients who initially respond to tamoxifen, and who subsequently progress, demonstrate a secondary response upon discontinuation of therapy (Legault-Poisson et al., 1979; Stein et al., 1983; Canney et al., 1987; Belani et al., 1989). Another more recent, and alarming, finding came from the NSABP-B14 adjuvant chemotherapy trial performed in ER-positive, node-negative breast cancer patients (Fisher et al., 1996,2001). In this study, it was demonstrated that disease-free survival in patients receiving tamoxifen improved by over 50\%. However, patients who received tamoxifen for longer than 5 years did no better, and possibly worse, than patients receiving tamoxifen for only 5 years (Fisher et al., 1996,2001). These findings suggested that tamoxifen did not simply fail but that it may be responsible for harm in some patients, possibly due to an antagonist/agonist switch. Given these findings, and the observation that tamoxifen could function as an agonist in the uterus, bone, and the cardiovascular system, we considered that resistance to this drug may arise as a consequence of 1) positive selection of a population of cells that is already poised to recognize tamoxifen as an agonist or 2) a drug-facilitated change in the processes that enable cells to distinguish between agonists and antagonists. It appeared, therefore, that a definition of the mechanism(s) by which tamoxifen agonist activity was manifest in some circumstances would help us to understand the molecular basis of resistance and may also shed light on SERM action.

\section{Definition of the Processes That Permit Cells to Distinguish Between Different ER-Ligand Complexes}

In established models of ER action, the role of estrogens was considered to be that of a switch that converted the transcriptionally inactive ER within the nuclei of target cells into a form that was capable of interacting with the 
regulatory regions within target genes and positively or negatively regulating transcription (McDonnell, 1999). Within the confines of this model, it was hard to understand how tamoxifen could manifest SERM activity, since it would predict that compounds were able to function as estrogens and activate or bind to the receptor and competitively inhibit estrogen binding and thus function as antagonists. Clearly, this was an oversimplification of what was occurring in the cell. Indeed, several major discoveries have occurred over the past decade that have revealed additional complexity in ER action and help to explain the pharmacology of SERMs such as tamoxifen. The most important of these are 1) the discovery of a second estrogen receptor, $\mathrm{ER} \beta ; 2$ ) the observation that the conformation of the two receptor subtypes is influenced by the nature of the bound ligand; and 3) the identification of receptor-associated comodulators, proteins that can enhance (coactivators) or repress (co-repressors) receptor transcriptional activity (Beekman et al., 1993; McDonnell et al., 1995; Onate et al., 1995; Kuiper et al., 1996; Mosselman et al., 1996; Brzozowski et al., 1997; Shiau et al., 1998; Pike et al., 1999,2001; McKenna et al., 1999; McKenna and O'Malley, 2000). All three of these activities have been shown to be important in SERM pharmacology and have been studied in great detail. For a more complete description of these particular advances, the reader is referred to several excellent reviews that have been published recently (McKenna et al., 1999; McKenna and O'Malley, 2000). However, the roles that these processes play in determining the agonist/antagonist activities of SERMs are highlighted below.

\section{The Role of ER $\beta$ in SERM Action}

Exploitation of differential expression of receptor isoforms, or subtypes, is a common mechanism by which tissue-selective drugs can be developed. Thus, with the identification of a second, genetically distinct ER, ER $\beta$, and the demonstration that its expression pattern was not identical to that of the previously identified receptor $\mathrm{ER} \alpha$, a potentially simple explanation for SERM pharmacology was anticipated (Kuiper et al., 1997). However, to date, we know very little about the role of ER $\beta$ in estrogen action. mRNA expression studies have demonstrated that ER $\beta$ is expressed in a wide variety of tissues (Shughrue et al., 1996; Kuiper et al., 1997). However, confirmation of the existence of significant levels of receptor protein in all mRNA-positive tissues has been more difficult and needs further investigation. Compounding this problem is the difficulty in defining the phenotypes in $\operatorname{ER} \beta$ knockouts where no consensus among investigators is yet apparent (Couse and Korach, 1999). Studies performed in vitro using reconstituted transcription systems indicate that, on ERE-containing promoters, both $\mathrm{ER} \alpha$ and $\mathrm{ER} \beta$ can activate transcription in response to agonists such as estradiol (McInerney et al., 1998; Hall and McDonnell, 1999). With one documented exception, however, it appears as if 
$\mathrm{ER} \alpha$ is a significantly more efficient activator of transcription than $\mathrm{ER} \beta$ (Harris et al., 2001). In cells where both subtypes are expressed, ER $\beta$ can dampen ER $\alpha$ activity and decrease overall sensitivity to agonists (Hall and McDonnell, 1999). The mechanism by which this occurs is not known but could represent competition between the receptors for the same DNA response element and/or heterodimerization of the weaker $\operatorname{ER} \beta$ with $\operatorname{ER} \alpha$. The inability to ascribe specific functions to $\mathrm{ER} \beta$ in vivo has limited our analysis of the role of this isoform on ER pharmacology to studies performed in vitro. In transfected cell systems, on classical ERE-containing promoters, it appears as if tamoxifen is always an ER $\beta$ antagonist (Hall and McDonnell, 1999). In contrast, some of these same cells are capable of supporting tamoxifen agonist activity when $\mathrm{ER} \alpha$ alone is expressed in an ectopic manner (Tzukerman et al., 1994). Interestingly, in cells where tamoxifen activates ER $\alpha$-mediated transcriptional activity, coexpression of ER $\beta$ completely suppresses this activity (Hall and McDonnell, 1999). Thus, it is possible that, whereas $\mathrm{ER} \alpha$ is required for tamoxifen partial agonist activity, the expression level of ER $\beta$ can regulate the magnitude of this activity. When analogous studies are performed on AP- 1 element-containing promoters, where ER binds indirectly to the promoter by contact with a prebound fos/jun complex, it was observed that the pharmacology of estrogens and SERMs is not the same as that observed on classical ERE-containing promoters (Paech et al., 1997). Notably, in AP1/ER $\alpha$ systems, estrogens activate and SERMs display a range of activities from partial to full agonists. However, when ER $\beta$ is studied in the same manner, it is noticed that estrogens antagonize and SERMs (all tested) activate transcription. The physiological significance of these results awaits the demonstration that the ER-AP1 interaction occurs in vivo. Considering what we now know, it appears as if tamoxifen can inhibit estradiol-activated transcriptional regulation by both $\mathrm{ER} \alpha$ and $\mathrm{ER} \beta$. Importantly, however, in some cell and promoter contexts, the tamoxifen-ER $\alpha$ complex can manifest partial agonist activity. Thus, it remains to be explained how the same ER $\alpha$-ligand complex can be recognized differently in different cells.

\section{Receptor Conformation and ER Pharmacology}

The ability of tamoxifen to manifest agonist activity in a cell-selective manner suggested that tamoxifen was not merely freezing ER in an apo-state, as the initial models proposed, but rather it must do something to the receptor that enables its unique pharmacological activities. Data to support this idea came from studies that used protease digestion assays to map the surfaces presented on ER $\alpha$ when occupied by different ligands (Beekman et al., 1993; McDonnell et al., 1995). Although this is not a sensitive technique, the conclusions of these studies were that tamoxifen was able to induce a change in ER $\alpha$ conformation that distinguished this receptor-ligand complex from apo-ER and that observed in 
the presence of estradiol or the pure anti-estrogens such as ICI182,780 (Beekman et al., 1993; McDonnell et al., 1995; Kraichely et al., 2000). Identical changes in conformation were observed when other SERMs were evaluated in this assay. Thus, it was not clear why tamoxifen and other SERMs such as raloxifene and nafoxidine were functionally distinct when assayed in vivo (McDonnell et al., 1995). Nevertheless, these early studies indicated that there was a link between the structure of the receptor-ligand complex and function. The general findings of these initial protease digestion studies were confirmed by subsequent crystallographic analysis of different ER $\alpha$-ligand complexes (Brzozowski et al., 1997; Shiau et al., 1998; Pike et al., 1999, 2001). As with the protease digestion experiments, crystallography has not yet been able to provide an obvious explanation for the observed functional differences between tamoxifen and other SERMs like raloxifene (Brzozowski et al., 1997; Pike et al., 1999). Regardless, these studies were able to demonstrate that ER can exist in states other than "off" and "on" and that receptor conformation was a key regulator of receptor pharmacology.

\section{Receptor Coactivators and Co-repressors}

The true significance of the finding that ER $\alpha$ could adopt different conformations in the presence of agonists, SERMs, and antagonists came with the discovery of receptor coactivators and co-repressors. The coactivator proteins, among them the p160 class members steroid receptor coactivator (SRC-1) and glucocorticoid receptor interacting protein (GRIP-1), interact with agonist-activated ER (Onate et al., 1995; Hong et al., 1996; Norris et al., 1998). This permits the ligand-activated receptor to contact the transcriptional apparatus and stabilize the preinitiation complex. In addition, some of these coactivators possess histone acetyl transferase (HAT) activity and recruit additional proteins with HAT activity like CBP and pCAF to the ligand-receptor complex (Spencer et al., 1997; McKenna et al., 1999). One major function of the DNA-bound ER-ligand complex, therefore, is to facilitate the acetylation of histones at target gene promoters, thus permitting a local decondensation of chromatin. Transcriptional corepressors (e.g., NcoR, SMRT), on the other hand, oppose the activity of coactivators by interacting with apo-ER, or that activated by antagonists, facilitating the assembly of large protein complexes that can deacetylate histones (McKenna et al., 1999). As a consequence, a localized condensation of chromatin and subsequent diminution of ER-mediated transcriptional activity are effected. With respect to drug-selective biological activities, the identification of a large number of different coactivators whose level of expression can differ between cells is important, as it suggests that differential cofactor recruitment may be a primary determinant of the tissue-selective actions of SERMs. This hypothesis is generally supported by recent studies that have tried to link the 
differential pharmacology of ER ligands to coactivator availability (Smith et al., 1997; Jepsen et al., 2000; Kraichely et al., 2000). Notwithstanding the successes to date, however, a final resolution of this issue, ascribing a given function to a specific coactivator, is likely to be several years away.

\section{Linking Receptor Conformation, Receptor Interacting Proteins, and Pharmacology}

When the crystal structure of estradiol-activated $\operatorname{ER} \alpha$, complexed with a fragment of GRIP-1, encompassing the nuclear receptor interacting domain (NR-box), was solved, a clear understanding of how agonists activate and antagonists inhibit ER transcriptional activity emerged (Shiau et al., 1998). Upon binding an agonist, it was demonstrated that there was a realignment of five of the $12 \alpha$-helices in the ER $\alpha$-ligand-binding domain such that a hydrophobic pocket on the receptor surface formed that enabled coactivator docking. It was also shown that tamoxifen and other antagonists induce distinctly different receptor conformations and prevent the formation of the hydrophobic coactivator-binding pocket (Brzozowski et al., 1997). These findings, which have been confirmed by a variety of biochemical approaches, suggest that the mechanism by which tamoxifen and estrogen manifest agonist activity are not the same. However, since one of the obligate steps in ER action appears to be the recruitment of a coactivator, it is likely that the coactivators with which ER-estradiol and ER-tamoxifen complexes interact are different or that the same coactivator can interact with ER in more than one way. As a first step in addressing this hypothesis, we used combinatorial phage display of random peptides to identify probes that could be used to map potential protein-protein interaction surfaces on ER $\alpha$ in the presence of tamoxifen and/or estradiol (Norris et al., 1999; Paige et al., 1999; Wijayaratne et al., 1999). Specifically, we screened large libraries of bacteriophage that expressed random peptides (11-19 amino acids in length) and identified a series of phage that expressed peptides that interacted specifically with ligand-activated $\operatorname{ER} \alpha$. The interaction of the peptides expressed by these phage with $\mathrm{ER} \alpha$ was assessed using a mammalian two-hybrid assay wherein the ability of a Gal4-peptide fusion to recruit an $\mathrm{ER} \alpha$-VP16 protein to a GAL4-responsive promoter was assessed (Figure 1A). The results of a typical analysis are shown in Figure 1B. One class of peptide, $\alpha / \beta$ I, interacted only with agonist-activated ER $\alpha$. Not surprisingly, when sequenced, all members of this class of peptides were found to encode peptides that contain an LXXLL motif, a sequence that has been shown to constitute the docking module on the p160 class of coactivators (Heery et al., 1997). Another of the peptides identified, $\alpha \mathrm{II}$, interacted with $\mathrm{ER} \alpha$ in the presence of either estradiol or tamoxifen. However, the most exciting finding was the identification of the peptides $\alpha / \beta \mathrm{III}$ and $\alpha / \beta \mathrm{V}$ that interacted only with tamoxifen-activated 
A

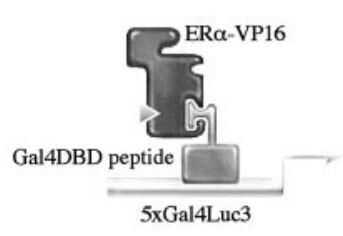

B

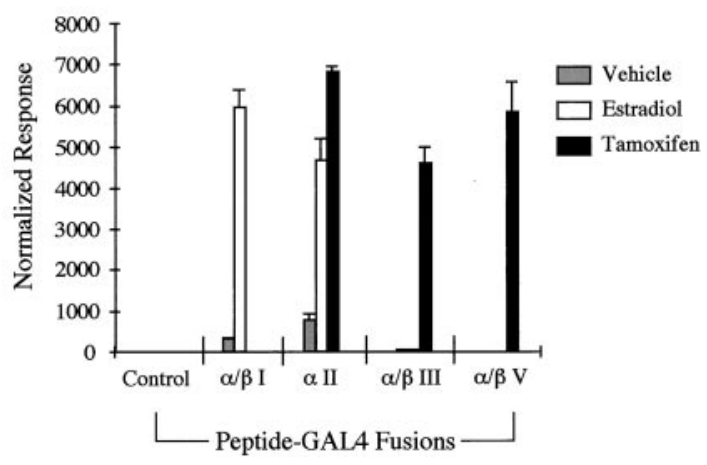

FIG. 1. Identification of peptides whose ability to interact with $\mathrm{ER} \alpha$ is influenced by the nature of the bound ligand. (A) A modified mammalian two-hybrid assay was used to assess the interaction of the peptides identified by phage display to interact with $\mathrm{ER} \alpha$-VP16 in the presence of the indicated ligands. (B) Each peptide was expressed as a fusion with the GAL4-DBD and its ability to interact with the ER $\alpha$-VP16 chimera was measured in transfected HepG2 cells on a Gal4-luciferase reporter, as described previously. All data were normalized to that of a hormone-unresponsive CMV- $\beta$-galactosidase reporter. [Reprinted from Norris JD, Paige LA, Christensen DJ, Chang C-Y, Huacani MR, Fan D, Hamilton PT, Fowlkes DM, McDonnell DP 1999 Peptide antagonists of the human estrogen receptor. Science 285:744-746. Copyright American Association for the Advancement of Science.]

$\mathrm{ER} \alpha$. These data confirmed that the structure of the ER $\alpha$-tamoxifen and $\operatorname{ER} \alpha$ estradiol complexes were not the same and suggested that unique protein-protein interaction surfaces were presented on $\mathrm{ER} \alpha$ following its interaction with these two compounds.

\section{The Agonist Activity of Tamoxifen and Estrogen Are Not Manifest in the Same Manner}

The primary objective of the phage-display experiments was to identify peptides that could be used to probe $\mathrm{ER} \alpha$ structure in the presence of different ligands (Paige et al., 1999). However, a quick review of a large number of studies that have used phage display in a similar manner on other targets indicated that the peptides that are identified in these types of studies usually bind to surfaces on proteins responsible for protein-protein interactions (Sparks et al., 1996; Kay et al., 1998). In light of this observation, we tested whether expression of the tamoxifen or estradiol-specific peptides in intact cells would have an impact on $\mathrm{ER} \alpha$ transcriptional activity (Norris et al., 1999). To address this issue, we took advantage of the fact that, in cultured liver hepatocellular carcinoma cells (HepG2), tamoxifen and $17 \beta$-estradiol both manifest agonist activity (Figure 
A

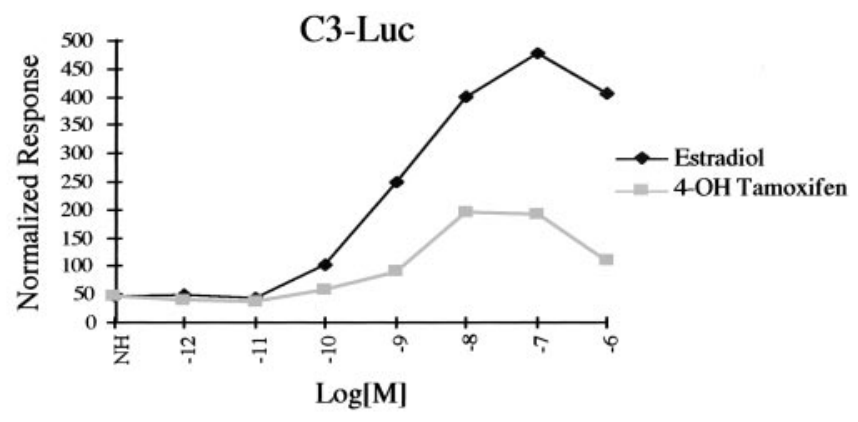

B

Estradiol

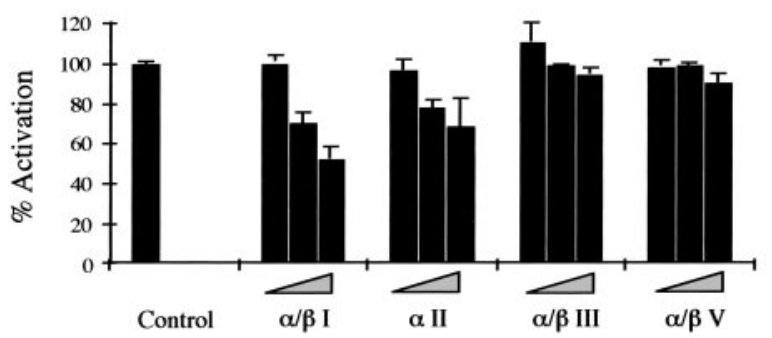

$\mathrm{C}$

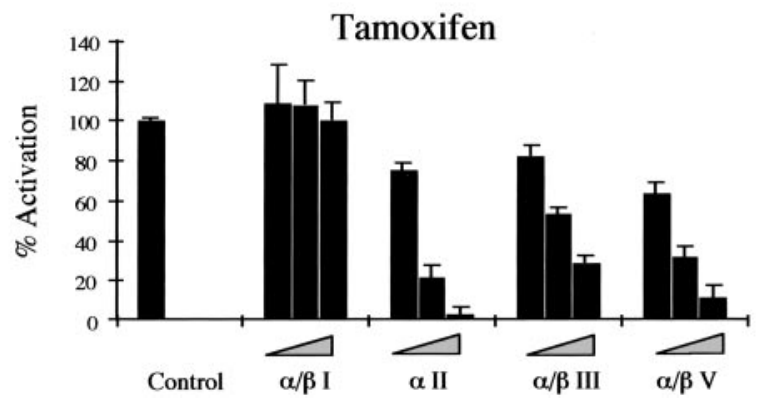

FIG. 2. Disruption of ER $\alpha$ /ERE-mediated transcriptional activity. (A) HepG2 cells were transfected with the estrogen-responsive C3-Luc reporter gene along with an ER $\alpha$ expression vector. Cells were induced with either estradiol or tamoxifen as indicated. NH, no hormone. (B) HepG2 cells were transfected as in (A), except that expression vectors for peptide-Gal4 fusions were included, as indicated. Control represents the transcriptional activity of estradiol $(10 \mathrm{nM})$-activated ER $\alpha$ in the presence of the Ga14DBD alone and is set at 100\% activity. Increasing amounts of input plasmid for each Gal4 peptide fusion is also shown (triangle), with the resulting transcriptional activity presented as percent activation of control. (C) As (B), except that 4-OH tamoxifen (10 nM) was used to activate the receptor. [Reprinted with permission from Norris JD, Paige LA, Christensen DJ, Chang C-Y, Huacani MR, Fan D, Hamilton PT, Fowlkes DM, McDonnell DP 1999 Peptide antagonists of the human estrogen receptor. Science 285:744-746. Copyright 1999 American Association for the Advancement of Science.] 
2A). Specifically, in HepG2 cells transfected with ER $\alpha$ and the complement 3-luciferase reporter, we were able to show that tamoxifen manifests partial agonist activity demonstrating 30\% the efficacy of estradiol (Norris et al., 1996,1999). When this experiment was performed in the presence of a vector expressing the $\alpha / \beta \mathrm{I}$ peptide, it was observed that estradiol, but not tamoxifen, agonist activity was inhibited (Figure 2B). Overexpression of the peptides that interacted specifically with tamoxifen-activated ER $\alpha$ inhibited tamoxifen agonist activity (Figure 2C), while having no effect on estradiol activity. Clearly, the mechanisms by which tamoxifen and estradiol manifest agonist activity in this model system were different. Furthermore, these latter findings suggest that the surface(s) with which the tamoxifen-specific peptides interact enables ER $\alpha$ to interact with a cofactor that facilitates its agonist activity. Since tamoxifen is a synthetic ligand, it must be assumed that this interaction is not physiological but pharmacologically induced and that agonist activity occurs as a consequence of an ectopic interaction of $\mathrm{ER} \alpha$ with some cofactor that is expressed in a cell-specific manner (Figure 3).

\section{The Surfaces Presented on ER Upon Binding Different SERMs Are Not Identical}

The concept that tamoxifen can facilitate an ectopic interaction of $\mathrm{ER} \alpha$ with a transcriptional coactivator was unanticipated. Ultimately, proof that this hypothesis is correct will require the identification of the coactivators that interact with the ER $\alpha$-tamoxifen complex and demonstration that their expression is sufficient to confer upon a cell the ability to recognize tamoxifen as an agonist. Studies aimed at identifying this elusive coactivator(s) are underway. In the meantime, however, we considered that it might be possible to test the relationship between receptor structure, coactivator recruitment, and pharmacology in an indirect manner. If the conformation of $\mathrm{ER} \alpha$ is an important determinant of how it interacts with coactivators and co-repressors, then we believed that it may be possible to regulate these interactions with compounds that enable ER $\alpha$ to adopt a conformation that is distinct from that formed in the presence of tamoxifen or $17 \beta$-estradiol. To test this hypothesis, a series of ER $\alpha$ agonists and antagonists were examined. Previous studies had determined them to have functional activities distinct from tamoxifen and estradiol, for their ability to facilitate the interaction of the ER-interacting phage described above (Willson et al., 1994,1997; Connor et al., 2001). This analysis was performed using an enzymelinked immunosorbent assay (ELISA) to assess the interaction of a representative phage from each class with different ER $\alpha$-ligand complexes (Figure 4). The results of this analysis indicated that these SERMs and antagonists induce a broad spectrum of conformational changes in ER $\alpha$ structure (Paige et al., 1999; Norris et al., 1999; Wijayaratne et al., 1999). Notably, the peptides $\alpha / \beta I I I$ and 


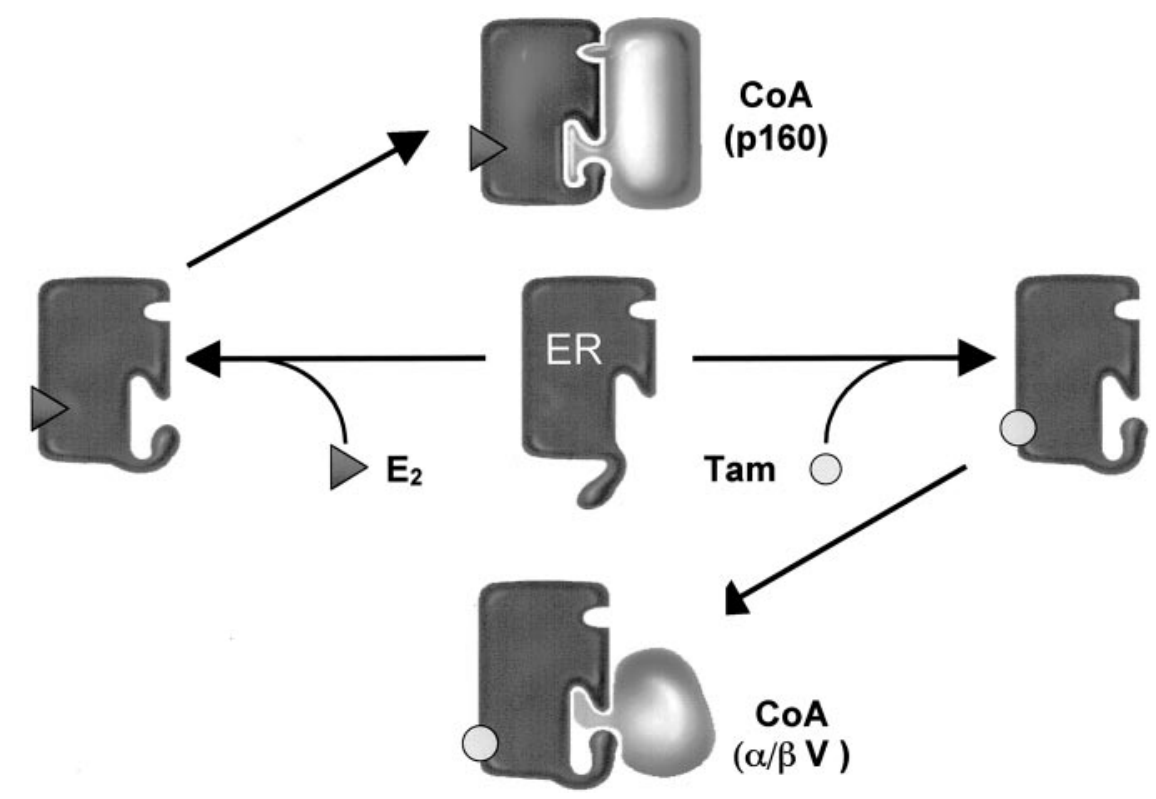

FIG. 3. Using peptide antagonists that inhibit specific protein-protein interactions, it has been demonstrated that the mechanisms by which estradiol and tamoxifen manifest agonist activity are dissimilar. Estradiol binding enables ER $\alpha$ to adopt a conformation that is compatible with the binding of a coactivator of the p160 class (i.e., SRC-1). Tamoxifen binding, on the other hand, induces a unique alteration in receptor structure that permits an ectopic interaction of the receptor with an as-yetunidentified coactivator that shares the binding characteristics of the $\alpha / \beta \mathrm{V}$ peptide. The existence of this coactivator is supported by the fact that peptides of the $\alpha / \beta \mathrm{V}$ class will inhibit tamoxifen, but not estradiol-mediated transcriptional activity, when expressed in target cells (see Figure 2).

$\alpha / \beta \mathrm{V}$ (tamoxifen specific) did not interact with $\mathrm{ER} \alpha$ when activated with ICI182,780 or GW5638 (or its 4-OH metabolite GW7604), compounds that have been shown previously to be biologically distinguishable from tamoxifen. Some binding of the "tamoxifen-specific" peptide $\alpha / \beta I I I$ to raloxifene-activated ER $\alpha$ was observed (Figure 4). Given what is known about the pharmacological activities of the ligands studied, it is likely that the conformational changes observed are functionally important. For instance, with the exception of their actions in the uterus, raloxifene and tamoxifen (the only compounds that can interact with the $\alpha / \beta \mathrm{V}$ peptide) have been shown to have similar biological activities (Sato et al., 1996). Consequently, it is not surprising that, given their similar mechanism of action, raloxifene was found to be ineffective as a treatment for tamoxifen-refractory breast cancer (Gradishar et al., 2000). In contrast, however, ICI182,780, a compound that our studies and more recent crystallographic analysis have indicated to induce a novel conformational change 

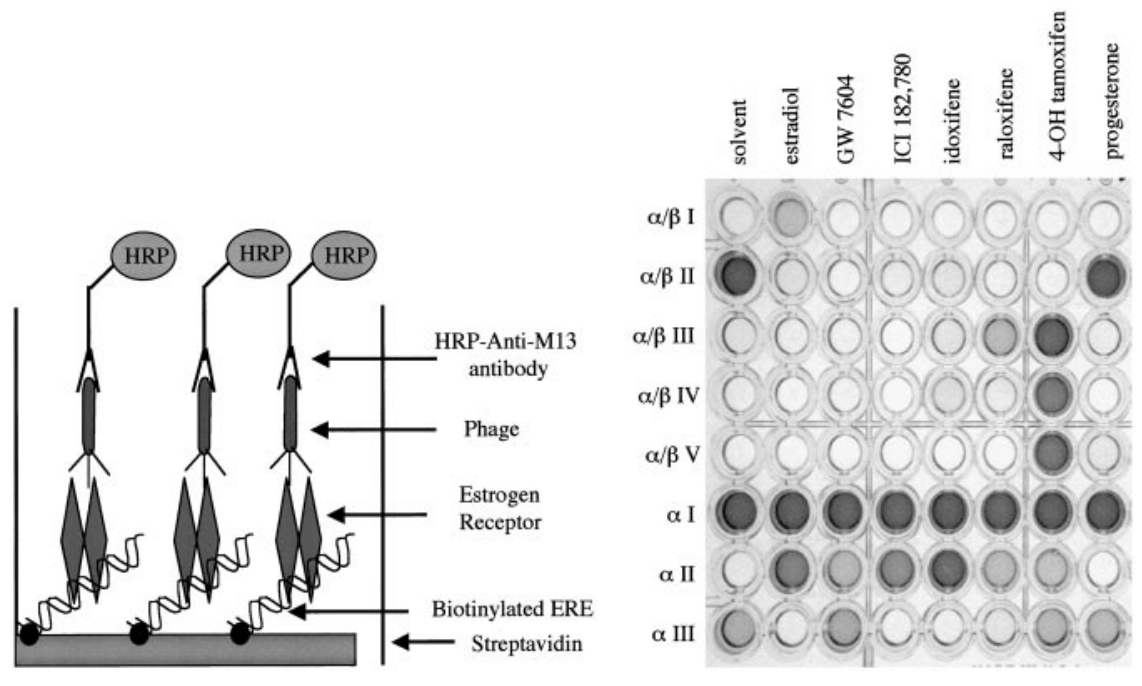

FIG. 4. Effect of ligands on ER $\alpha$ conformation. (Left panel) Phage ELISA assay: a biotinylated vitellogenin ERE was immobilized on 96-well plates coated with streptavidin. Following this step, $\mathrm{ER} \alpha$ was immobilized on the ERE and incubated in the presence of the indicated ligand. Subsequently, bacteriophage expressing the indicated peptides were added. Phage were incubated for 30 minutes at room temperature and washed five times to remove unbound phage. The bound phage were detected using an anti-M13 antibody coupled to horseradish peroxidase (HRP). (Right panel) The binding specificity of a series of peptide-expressing phage to ER $\alpha$ was evaluated in the presence of estradiol, SERMs, and the pure antagonist ICI182,780. Binding in the presence of progesterone was assessed for control purposes. The details of the screens that yielded the specific phage used in this analysis have been described previously (Paige et al., 1999). [Reprinted with permission from Wijayaratne AL, Nagel SC, Paige LA, Christensen DJ, Norris JD, Fowlkes DM, McDonnell DP 1999 Comparative analyses of the mechanistic differences among antiestrogens. Endocrinology 140:58285840. Copyright The Endocrine Society.]

in $\mathrm{ER} \alpha$, was found to be effective as a treatment for tamoxifen-refractory breast cancers (Howell et al., 1995; Norris et al., 1999; Paige et al., 1999; Wijayaratne et al., 1999; Pike et al., 2001). Taken together, these data are consistent with the hypothesis that novel cofactor binding surfaces are presented on ER $\alpha$ upon binding tamoxifen and other SERMs and that the availability of coactivators capable of interacting with the surfaces presented are the primary determinants of pharmacology.

\section{Confirmation of the Link Between ER Structure and Function in Vivo}

The in vitro studies performed over the past 10 years on ER pharmacology have enabled the derivation of molecular models with which to explain the 
different biological activities of ER ligands (McDonnell, 1999). However, the true test of whether these findings are physiologically relevant requires that the in vivo activity of a compound can be predicted based on its in vitro properties. In the past, studies have been done to show that ER ligands that functioned differently in vivo could subsequently be distinguished in vitro. However, to our knowledge, the reverse was never demonstrated with an ER ligand. Considering the usefulness of predictive in vitro assays, we decided to test whether compounds that were mechanistically distinct from tamoxifen were capable of inhibiting tamoxifen-refractory tumors. For these studies, we developed a tamoxifen-resistant MCF-7 breast cancer xenograft model (Connor et al., 2001). This was accomplished by growing MCF-7 cells in estrogenized athymic nude mice, then suppressing estrogen-stimulated growth by simultaneous treatment with tamoxifen. As expected, tamoxifen was initially found to be an effective inhibitor of tumor growth. However, after several months, the tumors resumed growing, despite the continued presence of tamoxifen. Indeed, we were able to demonstrate that these tumors had changed in such a way as to require tamoxifen for growth (Figure 5). This phenomenon has been observed by others using similar systems. Thus, it appears that it is relatively easy for breast cancer cells to switch from recognizing tamoxifen as an antagonist to seeing it as an agonist (Gottardis and Jordan, 1988; Osborne et al., 1992). As with any model system, it is always difficult to prove that it truly reflects the clinical situation and, in our case, that the mechanism by which MCF-7 cells become resistant to tamoxifen in mice is similar to how resistance arises in humans. However, given the clinical observations that 1) tamoxifen can function as an agonist in some organs, 2) a significant number of patients with tamoxifen-refractory breast cancer respond favorably to tamoxifen withdrawal, and 3) a tendency towards harm has been noted in breast cancer patients receiving tamoxifen for periods longer than 5 years, we are confident in the utility of the MCF-7 xenograft model. We propose, therefore, that the ability of tamoxifen to manifest agonist activity and resistance are integrally linked.

Our studies indicate that specific surfaces on tamoxifen-activated ER $\alpha$ enable it to manifest agonist activity by recruiting coactivators in some cells. Thus, we believed that a compound that bound ER but did not enable the presentation of the tamoxifen-specific surfaces would be an effective inhibitor of the growth of tamoxifen-refractory breast tumors. To test this hypothesis, we examined the ability of GW5638 (a compound that permitted ER $\alpha$ to adopt a conformational state distinct from that induced by tamoxifen and did not manifest agonist activity in cell systems where tamoxifen was a robust agonist) to inhibit the growth of tamoxifen-refractory breast tumors in athymic nude mice (Connor et al., 2001). The key results of this study, shown in Figure 6, are entirely consistent with our hypothesis. Specifically, it was demonstrated that tamoxifen-stimulated growth of these particular tumors was inhibited when 

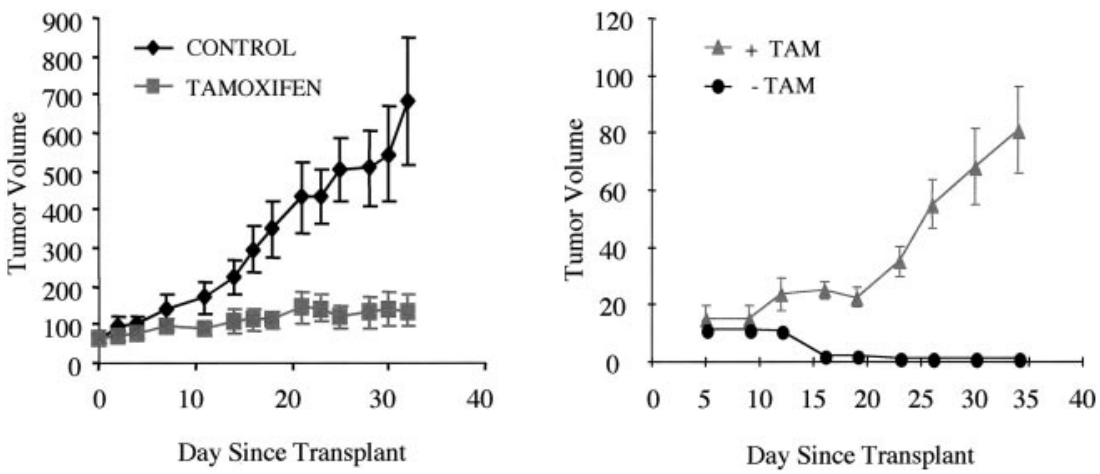

FIG. 5. MCF-7 cell xenografts switch from recognizing tamoxifen as an antagonist to an agonist. (Left panel) The growth of ER-positive MCF-7 cell xenografts is stimulated by estradiol and inhibited by tamoxifen. In this study, xenografts were implanted into estrogenized, ovariectomized mice. After tumors were established, mice were randomized and given vehicle (diamonds) or tamoxifen (squares) three times weekly. Day 0 represents the first day of treatment, approximately 4 weeks after tumor implantation. Data are expressed as mean tumor volumes ( $n=8-9$ mice/group). Animals that died during the experiment (five total) were included for the calculation of mean tumor volumes until their death. Eventually, the tamoxifen-inhibited tumors began to grow and appeared to be resistant. (Right panel) Putative tamoxifen-resistant tumors were implanted into both flanks of estrogenized, ovariectomized, athymic nude mice. One half of the animals in each group were left untreated, whereas one half received tamoxifen $(T A M)$ three times a week. Tamoxifen was administered as a 1.0-mg injection in $0.1 \mathrm{ml}$ of corn oil. Day 0 corresponds to the day of tumor implantation; treatment began immediately. Data are expressed as mean tumor volume. Bars, SE. [Reprinted with permission from Connor CE, Norris JD, Broadwater G, Willson TM, Gottardis MM, Dewhirst MW, McDonnell DP 2001 Circumventing tamoxifen resistance in breast cancers using antiestrogens that induce unique conformational changes in the estrogen receptor. Cancer Res 61:2917-2922. Copyright The American Association for Cancer Research.]

GW5638 was coadministered. In addition, although some growth of tumors persisted in the presence of GW5638 alone, it was significantly less than that which occurred in the presence of tamoxifen. Based on these findings, we propose a revised model to explain how cells are able to distinguish between different SERMs (Figure 7). Specifically, we propose that, in the presence of tamoxifen, ER undergoes a conformational change that enables it to interact in an ectopic manner with a coactivator that shares the binding characteristics of the $\alpha / \beta \mathrm{V}$ peptide described above (Figures 1 and 2). Thus, the presence or absence of this $\alpha / \beta \mathrm{V}$-like protein in a particular cell determines whether tamoxifen functions as an agonist or an antagonist. Upon binding a compound such as GW5638, ER adopts a conformational state that is distinct from that observed in the presence of tamoxifen. This receptor conformation does not permit the interaction of the $\alpha / \beta V$-like coactivator and, thus, no agonist activity in this environment is observed. The findings from the ongoing clinical trial of GW5638 


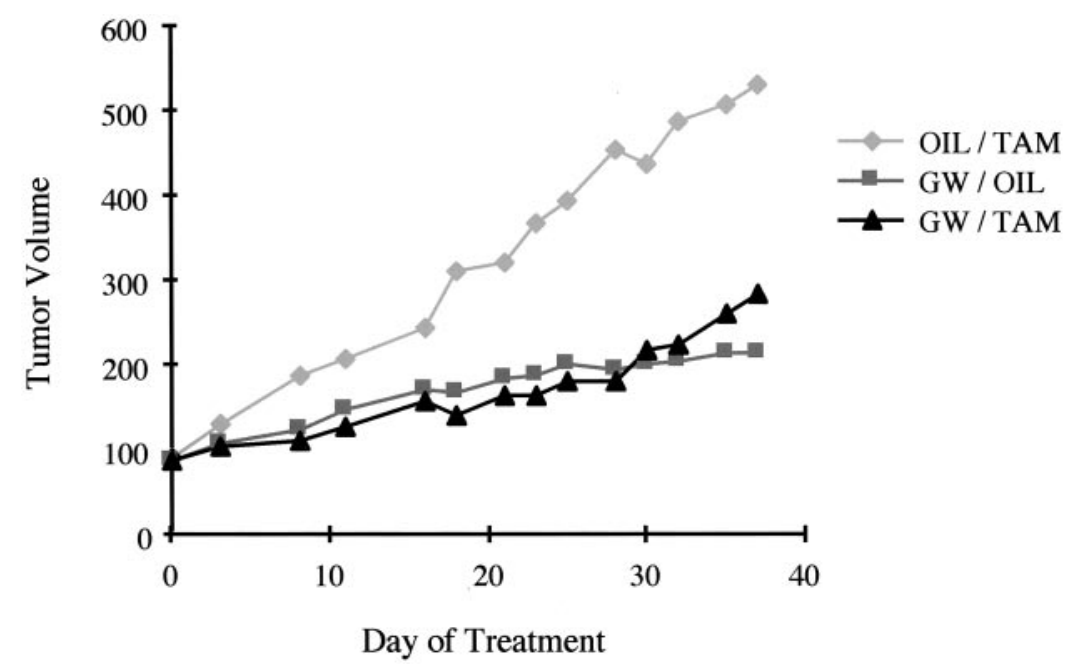

FIG. 6. Inhibition of tamoxifen-refractory tumors by the SERM GW5638. MCF-7 ${ }_{\mathrm{DU}} / \mathrm{TAM}$ tumors were implanted into athymic ovariectomized mice; tamoxifen was administered to promote tumor growth. After tumors were measurable, animals were randomized by tumor volume into treatment groups as follows: tamoxifen (diamonds), GW5638 (squares), and tamoxifen + GW5638 (triangles). Data are expressed as mean tumor volumes, $n=8-10$ mice/group. Tumor measurements of two animals that died randomly during the study were included in the mean volumes until the animal died. [Reprinted with permission from Connor CE, Norris JD, Broadwater G, Willson TM, Gottardis MM, Dewhirst MW, McDonnell DP 2001 Circumventing tamoxifen resistance in breast cancers using antiestrogens that induce unique conformational changes in the estrogen receptor. Cancer Res 61:2917-2922. Copyright The American Association for Cancer Research.]

in metastatic, tamoxifen-refractory disease will help to test the validity of this model.

\section{Final Comments}

In this review, the major processes that have been shown to be involved in modulating ER pharmacology have been considered. When considered together, it is now apparent that different ligands can induce different alterations in the structure of the ER and, by virtue of differential cofactor expression, cells can distinguish between the resultant receptor-ligand complexes. It is clear that the models presented here will continue to evolve as additional new processes that interface with ER are discovered and their physiological relevance established. For instance, it has been shown that receptor activity and response to ligands is modulated by signaling pathways initiated at the cell membrane that directly impinge on ER or modulate its activity by modifying the biochemical properties 


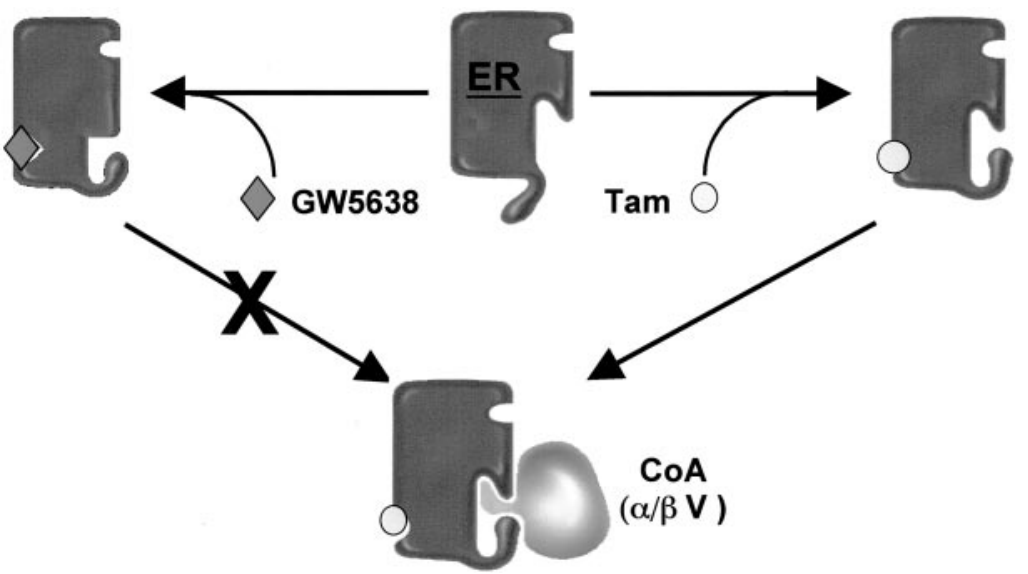

FIG. 7. Linking SERM action and receptor conformation. The studies that we have done on the mechanism of tamoxifen resistance have led us to believe that resistance and the ability of tamoxifen to manifest partial agonist activity in some contexts are related. Specifically, as mentioned above, it has been demonstrated that upon binding tamoxifen, ER adopts a conformation that does not allow it to interact with the p160 class of coactivators but with a coactivator whose binding properties resemble that of the $\alpha / \beta \mathrm{V}$ peptide. We have shown that this peptide (and presumably the corresponding coactivator) does not interact with the GW5638-activated ER, as the alteration in receptor structure induced by this particular ligand is not compatible with its interaction. Thus, a strong case is made for the treatment of tamoxifen-refractory breast tumors with SERMs/anti-estrogens whose mechanism of action is distinct from tamoxifen.

of coactivators and/or co-repressors (Power et al., 1991a,b; Ignar-Trowbridge et al., 1993,1996; Aronica et al., 1994; Mora and Brown, 2000; Rowan et al., 2000). In addition, it has been demonstrated in vitro that estrogens and antiestrogens can manifest nongenomic, ER-dependent activities in cultured cells. For instance, it has been shown that estrogens and some SERMs can activate mitogen-activated protein kinase (MAP-K) and phosphatidylinositol-3 kinase (PI3-K) in cultured cells (Improta-Brears et al., 1999). The physiological relevance of these latter activities is not clear, since they are only observed in cells that have been serum starved for extended periods, a situation that is not duplicated in vivo. Regardless, these findings demonstrate just how complex ER pharmacology is and suggest new avenues for intervention with new classes of pharmaceuticals.

\section{ACKNOWLEDGMENTS}

The author would like to thank Ms. Trena Martelon for help with the preparation of this manuscript. This work was supported by National Institutes of Health grants DK 48807 and CA90645 


\section{REFERENCES}

Aronica SM, Kraus WL, Katzenellenbogen BS 1994 Estrogen action via the cAMP signaling pathway: stimulation of adenylate cyclase and cAMP-regulated gene transcription. Proc Natl Acad Sci USA 91:8517-8521

Beall PT, Misra LK, Young RL, Spjut HJ, Evans HJ, LeBlanc A 1984 Clomiphene protects against osteoporosis in the mature ovariectomized rat. Calcif Tiss Int 36:123-125

Beekman JM, Allan GF, Tsai SY, Tsai M-J, O'Malley BW 1993 Transcriptional activation by the estrogen receptor requires a conformational change in the ligand binding domain. Mol Endocrinol 7:1266-1274

Belani CP, Pearl P, Whitley NO, Aisner J 1989 Tamoxifen withdrawal response. Report of a case. Arch Int Med 149:449-450

Black LJ, Sato M, Rowley ER, Magee DE, Bekele A, Williams DC, Cullinan GJ, Bendele R, Kauffman RF, Bensch WR, Frolik CA, Termine JD, Bryant HU 1994 Raloxifene (LY139481 HCI) prevents bone loss and reduces serum cholesterol without causing uterine hypertrophy in ovariectomized rats. J Clin Invest 93:63-69

Brzozowski AM, Pike AC, Dauter Z, Hubbard RE, Bonn T, Engstrom O, Ohman L, Greene GL, Gustafsson JA, Carlquist M 1997 Molecular basis of agonism and antagonism in the oestrogen receptor. Nature 389:753-758

Canney PA, Griffiths T, Latief TN, Priestman TJ 1987 Clinical significance of tamoxifen withdrawal response. Lancet 1:36

Clark JH, Markaverich BM 1988 Actions of ovarian steroid hormones. In: Knobil E, Neill J, eds. The Physiology of Reproduction. New York: Raven Press; 675-724

Clark JH, Peck EJ 1979 Female sex steroids:receptors and function. Monographs Endocrinol 14:1-245

Clemens JA, Bennet DR, Black LJ, Jones CD 1983 Effects of a new anti-estrogen, keoxifene (LY156758), on growth of carcinogen-induced mammary tumors and on LH and prolactin secretion. Life Sci 32:2869-2875

Connor CE, Norris JD, Broadwater G, Willson TM, Gottardis MM, Dewhirst MW, McDonnell DP 2001 Circumventing tamoxifen resistance in breast cancers using antiestrogens that induce unique conformational changes in the estrogen receptor. Cancer Res 61:2917-2922

Couse JF, Korach KS 1999 Estrogen receptor null mice: what have we learned and where will they lead us? Endocr Rev 20:358-417

Cummings SR, Eckert S, Krueger KA, Grady D, Powles TJ, Cauley JA, Norton L, Nickelsen T, Bjarnason NH, Morrow M, Lippman ME, Black D, Glusman JE, Costa A, Jordan VC 1999 The effect of raloxifene on risk of breast cancer in postmenopausal women: results from the MORE randomized trial. JAMA 281:2189-2197

Delmas PD, Bjarnason NH, Mitlak BH, Ravoux AC, Shah AS, Huster WJ, Draper M, Christiansen C 1997 Effects of raloxifene on bone mineral density, serum cholesterol concentrations, and uterine endometrium in postmenopausal women. N Engl J Med 337: 1641-1647

Early Breast Cancer Trialists' Collaborative Group 1998 Tamoxifen for early breast cancer: an overview of the randomised trials. Lancet 351:1451-1467

Ettinger B, Black DM, Mitlak BH, Knickerbocker RK, Nickelsen T, Genant HK, Christiansen C, Delmas PD, Zanchetta JR, Stakkestad J, Gluer CC, Krueger K, Cohen FJ, Eckert S, Ensrud KE, Avioli LV, Lips P, Cummings SR 1999 Reduction of vertebral risk in postmenopausal women with osteoporosis treated with raloxifene: results from a 3-year randomized clinical trial. Multiple Outcomes of Raloxifene Evaluation (MORE) Investigators. JAMA 282:637-645 
Fisher B, Dignam J, Bryant J, DeCillis A, Wickerham DL, Wolmark N, Costantino J, Redmond C, Fisher ER, Bowman DM, Deschenes L, Dimitrov NV, Margolese RG, Robidoux A, Shibata H, Terz J, Paterson AH, Feldman MI, Farrar W, Evans J, Lickley HL 1996 Five versus more than five years of tamoxifen therapy for breast cancer patients with negative lymph nodes and estrogen receptor-positive tumors. J Natl Cancer Inst 88:1529-1542

Fisher B, Dignam J, Bryant J, Wolmark N 2001 Five versus more than five years of tamoxifen for lymph node-negative breast cancer: updated findings from the National Surgical Adjuvant Breast and Bowel Project B-14 randomized trial. J Natl Cancer Inst 93:684-690

Gockerman JP, Spremulli EN, Raney M, Logan T 1986 Randomized comparison of tamoxifen versus diethylstilbestrol in estrogen receptor-positive or -unknown metastatic breast cancer: a southeastern cancer study group trial. Cancer Treatment Rep 70:1199-203

Gottardis MM, Jordan VC 1988 Development of tamoxifen-stimulated growth of MCF-7 tumors in athymic mice after long-term antiestrogen administration. Cancer Res 48:5183-5187

Gradishar W, Glusman J, Lu Y, Vogel C, Cohen FJ, Sledge GW Jr 2000 Effects of high dose raloxifene in selected patients with advanced breast carcinoma. Cancer 88:2047-2053

Hall JM, McDonnell DP 1999 The estrogen receptor $\beta$-isoform (ER $\beta$ ) of the human estrogen receptor modulates ER $\alpha$ transcriptional activity and is a key regulator of the cellular response to estrogens and antiestrogens. Endocrinology 140:5566-5578

Harper MJK, Walpole AL 1967 A new derivative of triphenylethylene: effect on implantation and mode of action in rats. J Reprod Fert 13:101-119

Harris HA, Henderson RA, Bhat RA, Komm BS 2001 Regulation of metallothionein II messenger ribonucleic acid measures exogenous estrogen receptor- $\beta$ activity in SAOS-2 and LNCaPLN3 cells. Endocrinology 142:645-652

Heery DM, Kalkhoven E, Hoare S, Parker MG 1997 A signature motif in transcriptional co-activators mediates binding to nuclear receptors. Nature 387:733-736

Hong H, Kohli K, Trivedi A, Johnson DL, Stallcup MR 1996 GRIP1, a novel mouse protein that serves as a transcriptional coactivator in yeast for the hormone binding domains of steroid receptors. Proc Natl Acad Sci USA 93:4948-4952

Howell A, DeFriend D, Robertson J, Blamey R, Walton P 1995 Response to a specific antiestrogen (ICI182,780) in tamoxifen-resistant breast cancer. Lancet 345:29-30

Hu XF, Veroni M, Luise Md, Wakeling A, Sutherland R, Watts CKW, Zalcberg JR 1993 Circumvention of tamoxifen resistance by the pure antiestrogen ICI 182,780. Intl J Cancer 55:873-876

Ignar-Trowbridge DM, Teng CT, Ross KA, Parker MG, Korach KS, McLachlan JA 1993 Peptide growth factors elicit estrogen receptor-dependent transcriptional activation of an estrogen-responsive element. Mol Endocrinol 7:992-998

Ignar-Trowbridge DM, Pimentel M, Parker MG, McLachlan JA, Korach KS 1996 Peptide growth factor cross-talk with the estrogen receptor requires the A/B domain and occurs independently of protein kinase C or estradiol. Endocrinology 137:1735-1744

Improta-Brears T, Whorton AR, Codazzi F, York JD, Meyer T 1999 Estrogen-induced activation of mitogen-activated protein kinase requires mobilization of intracellular calcium. Proc Natl Acad Sci USA 96:4686-4691

Ismail SM 1994 Effects of tamoxifen on uterus. Lancet 344:622-624

Jepsen K, Harmanson O, Onami TM, Gleiberman AS, Lunyak V, McEvilly RJ, Kurokawa R, Kumar V, Liu F, Seto E, Hedrick SM, Mandel G, Glass CK, Rose DW, Rosenfeld MG 2000 Combinatorial roles of the nuclear receptor corepressor in transcription and development. Cell 102:753-763

Karnik PS, Kulkarni S, Liu X-P, Budd GT, Bukowski RM 1994 Estrogen receptor mutations in tamoxifen-resistant breast cancer. Cancer Res 54:349-353 
Kay BK, Kurakin AV, Hyde-DeRuyscher R 1998 From peptides to drugs via phage display. DDT 3:370-378

Ke HZ, Paralkar VM, Grasser WA, Crawford DT, Qi H, Simmons HA, Pirie CM, ChidseyFrink KL, Owen TA, Smock SL, Chen HK, Jee WS, Cameron KO, Rosati RL, Brown TA, Dasilva-Jardine P, Thompson DD 1998 Effects of CP-336, 156, a new, nonsteroidal estrogen agonist/antagonist, on bone, serum cholesterol, uterus and body composition in rat models. Endocrinology 139:2068-2076

Kraichely DM, Sun J, Katzenellenbogen JA, Katzenellenbogen BS 2000 Conformational changes and coactivator recruitment by novel ligands for estrogen receptor- $\alpha$ and estrogen receptor- $\beta$ : correlations with biological character and distinct differences among SRC coactivator family members. Endocrinology 141:3534-3545

Kuiper GGJM, Enmark E, Pelto-Huikko M, Nilsson S, Gustafsson J-A 1996 Cloning of a novel estrogen receptor expressed in rat prostate and ovary. Proc Natl Acad Sci USA 93:5925-5930

Kuiper GGJM, Carlsson B, Grandien K, Enmark E, Häggblad J, Nilsson S, Gustafsson J-A 1997 Comparison of the ligand binding specificity and transcript tissue distribution of estrogen receptors $\alpha$ and $\beta$. Endocrinology 138:863-870

Kurl RN, Borthwick NM 1980 Clomiphene and tamoxifen action in the rat uterus. J Endocrinol 85:519-524

Legault-Poisson S, Jolivet J, Poisson R, Beretta-Piccoli M, Band PR 1979 Tamoxifen-induced tumor stumulation and withdrawal response. Cancer Treatment Rep 63:1839-1841

Love RR, Mazess RB, Barden HS, Epstein S, Newcomb PA, Jordan VC, Carbone PP, DeMets DL 1992 Effects of tamoxifen on bone mineral density in postmenopausal women with breast cancer. N Engl J Med 326:852-856

McDonnell DP 1999 The molecular pharmacology of SERMs. Trends Endocrinol Metab 10:301-311

McDonnell DP, Clemm DL, Hermann T, Goldman ME, Pike JW 1995 Analysis of estrogen receptor function in vitro reveals three distinct classes of antiestrogens. Mol Endocrinol 9:659-668

McInerney EM, Weis KE, Sun J, Mosselman S, Katzenellenbogen BS 1998 Transcription activation by the human estrogen receptor subtype $\beta(\mathrm{ER} \beta)$ studied with $\operatorname{ER} \beta$ and $\operatorname{ER} \alpha$ receptor chimeras. Endocrinology 139:4513-4522

McKenna NJ, Lanz RB, O’Malley BW 1999 Nuclear receptor coregulators: cellular and molecular biology. Endocr Rev 20:321-344

McKenna NJ, O'Malley BW 2000 An issue of tissues: divining the split personalities of selective estrogen receptor modulators. Nature Med 6:960-962

Mora JF, Brown M 2000 AIB1 is a conduit for kinase-mediated growth factor signaling to the estrogen receptor. Mol Cell Biol 20:5041-5047

Mosselman S, Polman J, Dijkema R 1996 ER $\beta$ : identification and characterization of a novel human estrogen receptor. FEBS Lett 392:49-53

Neven P 2000 Other selective oestrogen receptor modulators (SERMs) in development. Eur J Cancer 36:S65-S67

Norris JD, Fan D, McDonnell DP 1996 Identification of the sequences within the human complement 3 promoter required for estrogen responsiveness provides insight into the mechanism of tamoxifen mixed agonist activity. Mol Endocrinol 10:1605-1616

Norris JD, Fan D, Stallcup MR, McDonnell DP 1998 Enhancement of estrogen receptor transcriptionl activity by the coactivator GRIP-1 highlights the role of activation function 2 in determining estrogen receptor pharmacology. J Biol Chem 273:6679-6688

Norris JD, Paige LA, Christensen DJ, Chang C-Y, Huacani MR, Fan D, Hamilton PT, Fowlkes DM, McDonnell DP 1999 Peptide antagonists of the human estrogen receptor. Science 285:744-746 
Onate SA, Tsai S, Tsai M-J, O’Malley BW 1995 Sequence and characterization of a coactivator for the steroid hormone receptor superfamily. Science 270:1354-1357

Osborne CK 1998 Tamoxifen in the treatment of breast cancer. N Engl J Med 339:1609-1617

Osborne CK, Coronado E, Allred DC, Wiebe V, DeGregorio M 1991 Acquired tamoxifen resistance: correlation with reduced breast tumor levels of tamoxifen and isomerization of trans-4-hydroxytamoxifen. J Natl Cancer Inst 83:1477-1482

Osborne CK, Wiebe BJ, McGuire WL, Ciocca DR, DeGregorio MW 1992 Tamoxifen and the isomers of 4-hydroxytamoxifen in tamoxifen-resistant tumors from breast cancer patients. J Clin Oncol 10:304-310

Paech K, Webb P, Kuiper GGJM, Nilsson S, Gustafsson J-A, Kushner PJ, Scanlan TS 1997 Differential ligand activation of estrogen receptors ER $\alpha$ and ER $\beta$ at AP1 sites. Science 277:1508-1510

Paige LA, Christensen DJ, Grøn H, Norris JD, Gottlin EB, Padilla KM, Chang C-Y, Ballas LM, Hamilton PT, McDonnell DP 1999 Estrogen receptor (ER) modulators each induce distinct conformational changes in ER $\alpha$ and ER $\beta$. Proc Natl Acad Sci USA 96:3999-4004

Pike ACW, Brzozowski AM, Hubbard RE, Bonn T, Thorsell A-G, Engström W, Ljunggren J, Gustafsson J-Å, Carlquist M 1999 Structure of the ligand-binding domain of oestrogen receptor beta in the presence of a partial agonist and a full antagonist. EMBO J 18:4608-4618

Pike ACW, Brzozowski AM, Walton J, Hubbard RE, Thorsell A-G, Li Y-L, Gustafsson J-Å, Carlquist M 2001 Structural insights into the mode of action of a pure antiestrogen. Structure 9:145-153

Poulin R, Merand Y, Poirier D, Levesque C, Dufour JM, Labrie F 1989 Antiestrogenic properties of keoxifene, trans-4-hydroxytamoxifen and ICI164,384, a new steroidal antiestrogen, in ZR-75-1 human breast cancer cells. Breast Cancer Res Treatment 14:65-76

Power RF, Lydon JP, Conneely OM, O’Malley BW 1991a Dopamine activation of an orphan of the steroid receptor superfamily. Science 252:1546-1547

Power RF, Mani SK, Codina J, Conneely OM, O'Malley BW 1991b Dopaminergic and ligand-independent activation of steroid hormone receptors. Science 254:1636-1639

Rowan BG, Weigel NL, O'Malley BW 2000 Phosphorylation of steroid receptor coactivator-1: Identification of the phosphorylation sites and phosphorylation through the mitogen-activated protein kinase pathway. J Biol Chem 275:4475-4483

Sato M, Rippy MK, Bryant HU 1996 Raloxifene, tamoxifen, nafoxidine, or estrogen effects on reproductive and nonreproductive tissues in ovariectomized rats. FASEB J 905-912

Shiau AK, Barstad D, Loria PM, Cheng L, Kushner PJ, Agard DA, Greene GL 1998 The structural basis of estrogen receptor/coactivator recognition and the antagonism of this interaction by tamoxifen. Cell 95:927-937

Shughrue PJ, Komm B, Merchenthaler I 1996 The distribution of estrogen receptor- $\beta$ mRNA in the rat hypothalamus. Steroids 61:678-681

Sluyser M 1992 Role of estrogen receptor variants in the development of hormone resistance in breast cancer. Clin Biochem 25:407-414

Smith CL, Nawaz Z, O'Malley BW 1997 Coactivator and corepressor regulation of the agonist/ antagonist activity of the mixed antiestrogen, 4-hydroxytamoxifen. Mol Endocrinol 11:657666

Sparks AB, Hoffman NG, McConnell SJ, Fowlkes DM, Kay BK 1996 Cloning of ligand targets: Systematic isolation of SH3 domain-containing proteins. Nature Biotechnol 14:741-744

Spencer TE, Jenster G, Burcin MM, Allis CD, Zhou J, Mizzen CA, McKenna NJ, Onate SA, Tsai SY, Tsai M-J, O'Malley BW 1997 Steroid receptor coactivator-1 is a histone acetyltransferase. Nature 389:194-198

Stein W, Hortobagyi GN, Blumenschein GR 1983 Response of metastatic breast cancer to tamoxifen withdrawal: report of a case. J Surg Oncol 22:45-46 
Tonetti DA, Jordan VC 1995 Possible mechanisms in the emergence of tamoxifen-resistant breast cancer. Anti-Cancer Drugs 6:498-507

Touchette N 1992 Tamoxifen resistance in breast cancer. J NIH Res 4:67-72

Turner CH, Sato M, Bryant HU 1994 Raloxifene preserves bone strength and bone mass in ovariectomized rats. Endocrinology 135:2001-2005

Turner RT, Wakley GK, Hannon KS, Bell NH 1987 Tamoxifen prevents the skeletal effects of ovarian hormone deficiency in rats. J Bone Miner Res 2:449-456

Tzukerman MT, Esty A, Santiso-Mere D, Danielian P, Parker MG, Stein RB, Pike JW, McDonnell DP 1994 Human estrogen receptor transactivational capacity is determined by both cellular and promoter context and mediated by two functionally distinct intramolecular regions. Mol Endocrinol 8:21-30

Wijayaratne AL, Nagel SC, Paige LA, Christensen DJ, Norris JD, Fowlkes DM, McDonnell DP 1999 Comparative analyses of the mechanistic differences among antiestrogens. Endocrinology 140:5828-5840

Willson TM, Henke BR, Momtahen TM, Charifson PS, Batchelor KW, Lubahn DB, Moore LB, Oliver BB, Sauls HR, Triantafillou JA, Wolfe SG, Baer PG 1994 3-[4-(1,2-diphenylbut1-enyl)phenyl]acrylic acid: a non-steroidal estrogen with functional selectivity for bone over uterus in rats. J Med Chem 37:1550-1552

Willson TM, Norris JD, Wagner BL, Asplin I, Baer P, Brown HR, Jones SA, Henke B, Sauls H, Wolfe S, Morris DC, McDonnell DP 1997 Dissection of the molecular mechanism of action of GW5638, a novel estrogen receptor ligand, provides insights into the role of ER in bone. Endocrinology 138:3901-3911

Yaffe K, Sawaya G, Lieberburg I, Grady D 1998 Estrogen therapy in postmenopausal women: effects on cognitive function and dementia. JAMA 279:688-695

Zumoff B 1993 Hormone replacement and cardiovascular risk factors. N Engl J Med 329:1041-1043 